\title{
Lower tracheal and carinal resection associated with subtotal oesophagectomy for carcinoma of oesophagus involving trachea
}

\author{
D. T. THOM PSON \\ Department of Surgery, University of Rhodesia, Salisbury, Rhodesia
}

The problem of the patient with a carcinoma of the oesophagus involving the lower trachea and one or other main stem bronchus is discussed. An operation in which the carina was excised and both main bronchi were re-anastomosed to the trachea in association with a subtotal oesophagectomy is described. The criteria for deciding to undertake such an operation are discussed.

Involvement of the tracheobronchial tree by carcinoma of the oesophagus has always been regarded as a contra-indication to surgical resection or radiotherapy, the danger of producing an oesophagotracheal or bronchial fistula in the latter form of treatment precluding its use.

Management has been confined, generally, to the insertion of a plastic tube through the malignant stricture, thus allowing the patient to take a fluid diet. Occasional surgical attempts at bypassing the lesion with jejunum or colon have been described as well as excision of the bronchial lesion and repair of the defect with pericardium. The following case in which oesophageal tumour and the entire carina were removed and both lungs reanastomosed is reported.

\section{CASE REPORT}

A 34-year-old man was seen in February 1972 complaining of difficulty in swallowing for one week, associated with vomiting after taking solid food, but he was able to swallow fluids.

Apart from obvious loss of weight with muscle wasting, suggesting inadequate nutrition for longer than one week, there was no abnormality on general physical examination, and the patient was a relatively fit young man.

Oesophagoscopy showed a nodular, somewhat fleshy tumour occluding the oesophagus at $27 \mathrm{~cm}$ from the incisor teeth. At bronchoscopy there was a heaping forward of the posterior wall of the trachea just proximal to the carina though the tumour had not yet eroded through the tracheal mucosa. Biopsy from the tumour confirmed that it was a squamous-cell carcinoma.

At operation the left chest was explored first through the bed of the eighth rib. The involvement of the lower trachea could be felt after mobilization of the oeso- phagus. There was little invasion of the mediastinum, and it was decided to proceed to resection. The diaphragm was opened and the stomach mobilized into the chest through the oesophageal hiatus. After closure of the diaphragm and chest the patient was rotated to allow entry into the right chest through the fifth rib bed. The azygos vein was divided and the tumour became visible. It was seen to be invading the posterior wall of the lower trachea and a line of separation could not be established. It was decided to proceed to resection of the carina and origins of both left and right main bronchi.

The endotracheal tube was removed and replaced by a longer one which could extend into the left main bronchus.

The mobilized stomach was brought into the right chest and divided from the cardia to the lesser curvature, the cut edges being closed in two layers to construct a blind tube; this was left in the right mediastinal gutter. The oesophagus was stripped from the posterior wall of the trachea (a sizeable defect lined by neoplastic tissue being left) and divided just within the thoracic inlet, the remaining cut end being covered by a lightly tied swab.

The trachea was divided above the lesion as were the left and right main bronchi just distal to it (Fig. 1). Anastomosis was achieved by keeping the endotracheal tube impacted in the left main bronchus while the adjacent sides of the cartilaginous portions of the two main bronchi were sutured to create a new 'carina'. Once the 'carina' was reconstructed, the endotracheal tube was withdrawn into the trachea for a minute and a half, which time, from previous experience with tracheobronchial anastomoses, usually allowed a single stitch to be inserted and tied. The tube was reinserted into the left main bronchus, guided by the surgeon, and the lung was inflated for a minute before withdrawal into the trachea was again effected (Fig. 2). The right lung was allowed to deflate, thus permitting unobstructed access to the anastomotic site.

By repeating this procedure the posterior stitches 


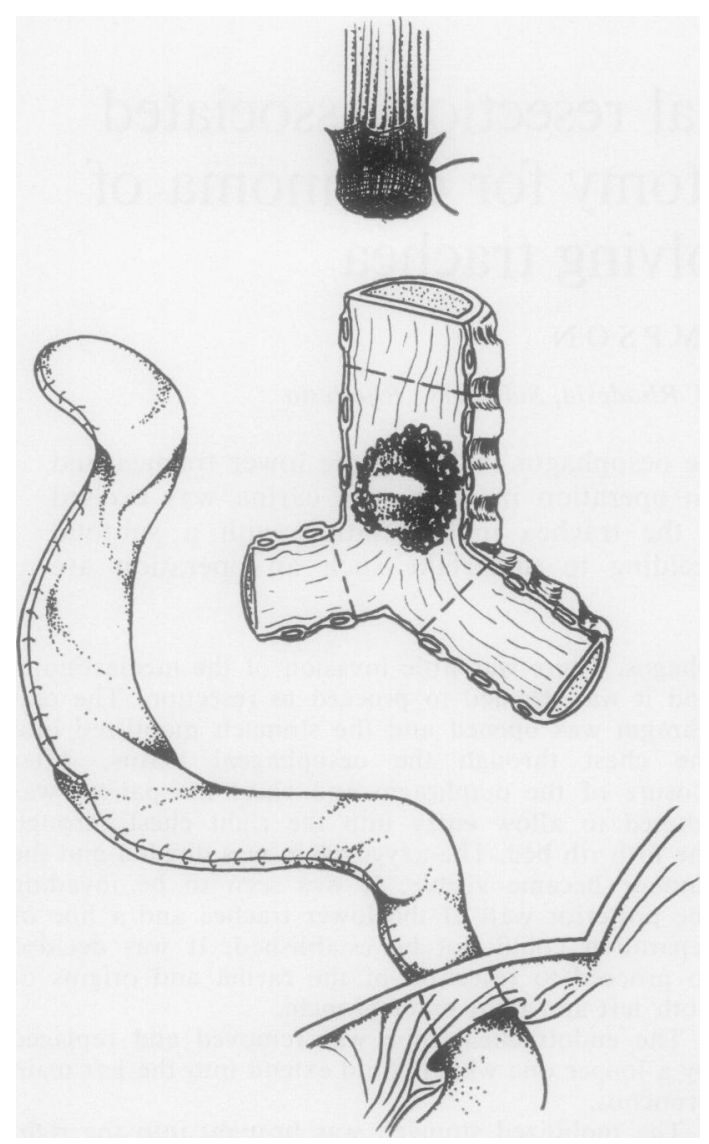

FIG. 1. Surgical situation after removal of oesophagus.

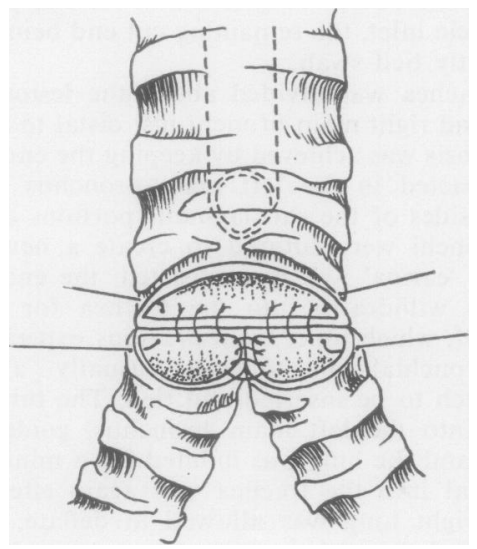

FIG. 2. Reconstruction of 'carina' and posterior wall. were inserted, after which the tube remained in the $\stackrel{\overrightarrow{\vec{S}}}{\overrightarrow{7}}$ left main bronchus, while the stitches approximating $O$ the cartilaginous portions of the trachea and bronchi $\frac{\bar{O}}{}$ were inserted. Throughout the anastomosis 00 catgut $\frac{\sigma}{\sigma}$ sutures were used. Acriflavine was poured into the $\vec{\nabla}$ chest cavity to test for air leaks on positive pressure 응 inflation. It was decided to accept the very small air के leak that was demonstrated, and no further stitches $\vec{\circ}$ were inserted. Both lungs inflated well. Antibiotic powder was placed around the anastomotic site.

The stomach was stitched lightly to the upper oeso- $\stackrel{O}{\omega}$ phageal remnant, two intercostal drain tubes were $\vec{x}$ inserted, one to the apex, and the chest was closed.

The patient was placed on his back and the cervical $\infty$ oesophagus was identified through a 'thyroid' collar N incision. The oesophagus, with stomach attached, was of delivered into the wound, and the oesophagus was divided at about the level of the thyroid gland, care 은 being taken to preserve the right recurrent laryngeal $\rightarrow$ nerve. An end-to-side oesophagogastric anastomosis $?$ with interrupted black silk sutures was achieved, and after insertion of a Ryle's tube into the stomach tube $\stackrel{\Im}{\supset}$ the wound was closed with drainage.

The patient's postoperative course was satisfactory, though an aspiration bronchoscopy as an alternative to physiotherapy was carried out on the second postoperative day to clear his secretions. Active physiotherapy with coughing was not practised until the fifth $\bar{\partial}$ postoperative day. After speaking normally on the first postoperative day, the patient lost his voice and $\Phi$ it did not begin to return until four weeks later.

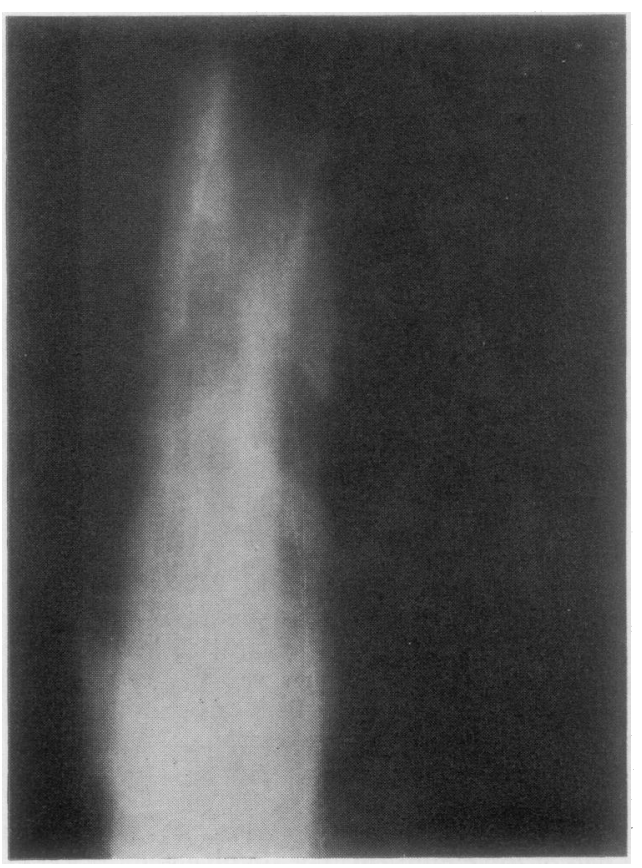

FIG. 3. Tomograph of reconstructed lumen of trachea. 
Laryngoscopy two weeks after operation showed a paralysed left cord and some feeble movement of the right.

This inability of the cords to protect the bronchial tree gave rise to anxiety when he started to swallow fluids, which were started on the fifth postoperative day and which tended to spill over into the trachea. This did not happen with solids. He was encouraged to take only small sips of fluids, and this avoided further inhalation. The patient was up and about by the tenth postoperative day. There was no infection at the three incision sites, nor did lung or mediastinal infection occur.

Bronchoscopy two weeks after anastomosis showed a 'carina' healing well with no narrowing at the anastomotic site. The oesophagogastric anastomosis was also inspected and found to be healing well. Later studies showed adequate passage of barium through into the small intestine, and tomography (Fig. 3) demonstrated an anastomosis that did not narrow the tracheal lumen.

\section{DISCUSSION}

In the African patient in the northern parts of Rhodesia and Malawi, carcinoma of the oesophagus is a common disease. These patients present to hospital when the condition is well advanced. The usual palliative management, namely the insertion of a plastic tube through the constricting neoplasm, is a most unsatisfactory method of treatment because the rural African's staple diet is 'sadza', a mixture of maize meal, vegetables, and meat, and to send a patient out from hospital to his rural environment to take a fluid diet is to ignore the sociological and financial problems involved. A high-protein fluid diet is an expensive one, certainly beyond the means of the average rural African.

The problem, therefore, facing the clinician responsible for the care of patients with advanced carcinoma of the oesophagus is one of restoring the ability of the patient to swallow a solid diet, if this is possible, with less concern for the ultimate long-term survival. In the cachectic elderly patient with advanced disease surgery is, of course, impossible and the patient's death in hospital is the rule; treatment is a matter of making the patient as comfortable as possible by whatever palliative measures seem the most appropriate.

However, carcinoma of the oesophagus in Rhodesia is seen commonly in the younger middleaged adult and is almost exclusively a male disease. At this university teaching hospital over a twoyear period 130 patients with squamous-cell carcinoma of the oesophagus were seen and of these $60 \%$ were in the age-group 41-60 years and only two were female. This sex and age distribution of the disease contrasts markedly with comparable figures in British patients, in whom $40 \%$ are females and the average age of the patient is 65 years. The lesion in a high proportion of cases is seen in the middle or upper thirds, and involvement of the bronchus or trachea is quite common.

The insertion of a plastic tube for high oesophageal carcinomata is often uncomfortable for the patient in that he is aware of its presence, particularly if it lies behind the trachea.

In our patient it was decided to proceed to this resection because the patient was young and in relatively good condition, and because his future without operation was hopeless. It may be argued that a resection of such magnitude is not justified in this disease, but because considerable experience in tracheal and tracheobronchial anastomosis has been gained, and because neoplastic involvement of the bronchial tree by oesophageal neoplasm is a common problem, it was decided to proceed. The younger, fit patient who, on exploration, has a carcinoma involving the tracheobronchial tree, which has not spread extensively, should be submitted to total excision of the lesion.

The author wishes to express his gratitude to the anaesthetist, Dr. C. Thompson, whose conscientious attention to detail contributed greatly to the success of this operation and to the patient's relatively uncomplicated postoperative course. My thanks also go to the physiotherapist and nurses in the Intensive Care Unit of Harari Hospital for their constant and vigilant care.

\section{BIBLIOGRAPHY}

Barnard, P. M., Kilroy, E. G., and Kennedy, J. H. (1966). Inoperable cancer of the esophagus, use of the Mousseau-Barbin tube in palliative surgery. $J$. thorac. cardiovasc. Surg., 51, 125.

Celestin, L. R. (1959). Permanent intubation in inoperable cancer of the oesophagus and cardia; a new tube. Ann. roy. Coll. Surg. Engl., 25, 165.

Grillo, H. C., Bendixen, H. H., and Gephart, T. (1963). Resection of the carina and lower trachea. Ann. Surg., $158,889$.

Judd, D. R., and Codd, J. (1967). Palliation for malignant esophagotracheal fistula. J. thorac. cardiovasc. Surg., 54, 751 .

Lawler, M. R., Gobbel, W. G., Killen, G. A., and Daniel, R. A. (1969). Carcinoma of the esophagus. J. thorac. cardiovasc. Surg., 58, 609.

Leon, W., Strug, L. H., and Brickman, I. D. (1971). Carcinoma of the esophagus-a disaster. Ann. thorac. Surg., $11,583$.

Luke, S. I. (1969). An approach to the management of carcinoma of the oesophagus in the Bantu. S. Afr. med. J., 43, 674 . 
Martini, N., Goodner, J. T., D'Angio, G. J., and Beattie, E. J. (1970). Tracheoesophageal fistula due to cancer. J. thorac. cardiovasc. Surg., 59, 319.

Maunz, D. L., and Crandell, W. B. (1969). Colon interposition for palliation of malignant esophagotracheal fistula. Amer. J. Surg., 117, 599.

Ong, G. B., and Kwong, K. H. (1970). Management of malignant esophagobronchial fistula. Surgery, 67, 293.

Palmer, E. D. (1970). Experiences with management of malignant oesophago-respiratory fistula by peroral esophageal prosthesis. Gastro-intest. Endoscopy, 17, 12.

Procter, D. S. (1968). Carcinoma of the oesophagus. A review of 523 cases. S. Afr. J. Surg., 6, 137.

Scanlon, E. F. (1970). Pitfalls in the surgical management of carcinoma of the esophagus. Surg. Clin. N. Amer., 50, 75.
Symonds, C. J. (1887). The treatment of malignant stricture of the oesophagus by tubage or permanent catheterism. Brit. med. J., 1, 870.

Thomas, T. V., and Ransdell, H. T. (1970). Surgical treatment of esophageal carcinoma. Postgrad. med., 47, 131.

Thompson, D. T. (1966). Tracheal resection with left lung anastomosis following right pneumonectomy. Thorax, 21,560 .

- Doyle, J. A., and Roncoroni, A. J. (1969). Carinal resection, left pneumonectomy, and right lung anastomosis for adenocystic basal cell carcinoma (cylindroma). Thorax, 24, 752.

Waddington, J. K. B., and Bickford, B. J. (1962). The use of the Mousseau-Barbin tube for palliation in carcinoma of the oesophagus and cardia. Brit. J. Surg., 49, 522. 